\title{
Effectiveness of Visual Inspection with Acetic Acid versus Papanicolaou Smear for Cervical Cancer Screening at Kirtipur Hospital
}

\author{
Pradhan $\mathbf{P}^{1}$, Shrestha $\mathbf{S}^{1}$, Dangal $\mathbf{G}^{2}$, Bhattachan $\mathrm{K}^{2}$ \\ ${ }^{1}$ Department of Obstetrics and Gynaecology, Kirtipur Hospital, Kirtipur, Kathmandu, Nepal, ${ }^{2}$ Department of Obstetrics \\ and Gynaecology, Kathmandu Model Hospital, Kathmandu, Nepal.
}

Received: 4-Oct-2016 ; Accepted: 17-Dec-2016

\begin{abstract}
Aims: The aim of this study was to compare the accuracy of detecting precancerous cervical cells, via a visual inspection of the cervix and an application of acetic acid (VIA) with the Papanicolaou (Pap) smear,to screen for cervical cancer in resource poor countries.
\end{abstract}

Methods: The study involved 189 women between the ages of 30-60 years, who attended the Gynaecological Out Patient Department at Kirtipur hospital from 1st December 2014 to 31st March 2015. A VIA and Pap smear was done in all women, with cervical biopsies conducted in VIA positive women.

Results: The majority of these women were in the age range of 30-39 years, non-smokers, housewives, multipara and nonusers of contraception. Of the tested group $8(4.2 \%)$ had a history of post coital bleeding, $64(21.2 \%)$ presented with lower abdominal pain, $64(33.9 \%)$ presented with suspected abnormal vaginal discharge and $34(17.98 \%)$ with dysfunctional uterine bleeding. Out of 189 women the VIA was positive in $5(2.62 \%)$ and a Pap smear was positive in 2 (1.1\%). Bycomparison to a Pap smear the VIA has an accuracyof $100 \%$, specificity $98.4 \%$, positive predictive value $40 \%$ and negative predictive value $100 \%$.

Conclusions: A visual inspection of the cervix with acetic acid performed by a qualified physician is a suitable alternative for precancerous cell screening in low resource settings.

Keywords: acetic acid; cervical cancer; Pap smear; Papanicolaou smear; visual inspection.

\section{INTRODUCTION}

Cervical cancer remains the second most common cancer in women worldwide ${ }^{1}$ and the leading cause of cancer related death. Of the approximately 500,000 new cases reported annually almost 300,000 women will die ${ }^{2}$ with $88 \%$ of those occurring in developing countries. ${ }^{3}$ It is estimated that more than 10,000 new cases of invasive cancer arise in Nepal each year and that 26,000-45,000 women currently have an undiagnosed precancerous lesion at this moment. ${ }^{4}$

Most developed countries have shown a dramatic reduction in the incidence and death rate from cervical cancer following the implementation of organized screening and awareness programs. It has been estimated that only $5 \%$ of women in developing countries have been screened for cervical dysplasia in the past 5 years compared with $85 \%$ in developed countries. $^{5}$

\section{CORRESPONDENCE}

Dr. Peru Pradhan,

Department of Obstetrics and Gynaecology,

Kirtipur Hospital, Kirtipur, Kathmandu, Nepal.

Email:pradhanperu@gmail.com,

Phone: +977-9851170155.
In a developing country like Nepal it is difficult to implement new organized screening programs such as liquid based cytology, HPV DNA testing or automated Pap testing. Conventional Papanicolaou (Pap) smear testing requires good infrastructure, specialized personnel and multiple visits by the woman for follow up and/or treatment, it can become time consuming and expensive. Whilst a visual inspection with administration of acetic acid (VIA) is a cost effective, simple and real-time screening with accuracy that is comparable to a good quality Pap smear. ${ }^{6}$ The cervix is easily accessible and has a longstanding precancerous stage known as intraepithelial lesion $(\mathrm{CIN})^{7}$ and unlike many cancers, cervical cancer can be prevented with appropriate screening and treatment. VIA could be a possible alternative screening tool for early detection of cervical cancer in Nepal where cervical cancer is the most frequent cause of cancer death among the female population.

\section{METHODS}

This is a comparative study conducted among 189 women, who attended the Gynaecological Outpatient Clinic at Kirtipur Hospital from 1 December 2014 
to 31 March 2015 . The study was ethically approved by IRC (Institutional Review Committee) of phectNepal. In this study, women between the ages of 3060 years were included with a broad cross section of those who were unmarried, pregnant, had active vaginal bleeding, had a recent Pap smear, hada frank growth on the cervix, hada hysterectomy and hada previous history of treatment for cancerous lesions were included but patients with a history of an allergic reaction to acetic acid were excluded. All relevant obstetric and gynaecological history were taken as well as information such as smoking habits, number of sexual partners, any abnormal vaginal discharge, postcoital bleeding, menstrual irregularities and age of marriage were also recorded. All women involved in this study were educated about cancer of the cervix, and all procedures to be performed were explained with written informed consent given by each.

All women were given a general physical examination and, after proper positioning, a local vulvar examination was performed. Cusco's vaginal speculum was inserted and fixed to view the cervix. Any visible abnormal discharge was noted, the squamo-columnar junction was visualized and with the hooked end of Ayre's spatula the squamo-columnar area was scraped gently around the circumference and the collected material was transferred to a glass slide that was put into a container with $95 \%$ alcohol. Following the Pap smear, abnormal discharge such as blood and mucus from the cervixwas removed by normal saline soaked cotton swabs, then a solution of 5\% acetic acid was applied to the cervix using a cotton swab. The cervix was visualized after one minute using an adequate light source and the appearance of any distinct acetowhite opaque areas at the transformation zone touching the squamocolumnar junction was considered to be a positive result. The women with positive results were educated about colposcopic examination and cervical biopsy. Biopsies were taken using punch biopsy forceps from the white and opaque areas within the transformation zone, the specimen were then transferred inside a container in formalin and sent to the pathological laboratory at Kathmandu Model Hospital. Results were collected then recorded for analysis using the Chi-square statistical test.

\section{RESULTS}

During the study period 189 women attending the Gynaecological Out Patient Department of Kirtipur Hospital were enrolled, a majority of the women were of the age group 30-39years, non-smoker, housewives, multipara and non-user of contraception. Only $8(4.2 \%)$ women had a history of postcoital bleeding, $64(21.2 \%)$ women had lower abdominal pain, 64 (33.9\%) women presented with suspected abnormal vaginal discharge and 34 (17.98\%) women with dysfunctional uterine bleeding.

Table 1.Age and parity of the study population.
\begin{tabular}{|lll|}
\hline Age in years & Number & Percentage \\
\hline $30-39$ & 90 & 47.6 \\
$40-49$ & 74 & 39.1 \\
\hline $50-60$ & 25 & 13.3 \\
Parity & & \\
Nullipara & 8 & 4.2 \\
P1-4 & 171 & 90.5 \\
\hline >=P5 & 10 & 5.3 \\
\hline
\end{tabular}

Table 2.Relation between Pap smear and VIA.

\begin{tabular}{|lllll|}
\hline VIA & Pap positive & Pap negative & Total & \\
\hline Positive & 2 & 3 & 5 & $\mathrm{p}-0.001$ \\
Negative & 0 & 184 & 184 & \\
Total & 2 & 187 & 189 & \\
\hline
\end{tabular}

Out of five VIA positive cases two were also Pap positive. The table above shows the probability of havinga Pap positiveif the VIA is positiveas 0.001 .

Sensitivity of the VIA and Pap test were 100\%, whereas specificity was $98.4 \%$, positive predictive value was $40 \%$ and negative predictive value was $100 \%$. Biopsies were taken in all VIA positive women. Out of 5 VIA positive women $2(40 \%)$ women were found to be positive for intraepithelial cervical neoplasia with a biopsy.

\section{DISCUSSION}

Cervical cancer is the leading cause of morbidity and mortality among women worldwide. With a successful screening programme $80 \%$ of incidences and mortality due to cervical cancer have declined in developed countries. Screening programs have beenintroduced into developing countries since the early 1980's yet have failed to reduce the mortality rate. $\mathrm{WHO}$, in 2002 , estimated that only $5 \%$ of womenin developing countries are screened appropriately. Likely reasons for failure in screening programs include lack of funding, insufficient access in rural areas,where most of the population 
in developing countries reside, lack of awareness/ education as to the need for screening and poor follow up. ${ }^{7}$ Thus visual inspection using acetic acid (VIA) has emerged as a promising, cost effective, non-cytological based alternative for economically underprivileged geographical regions. The molecular basis is that acetic acid causes dehydration of cells and surface coagulation of cellular proteins thereby reducing the transparency of the cervical epithelium. These changes are more pronounced in abnormal epithelium due to greater nuclear density and consequently a higher concentration of proteins. A positive test is based on the detection of welldefined acetowhite epithelium one minute after the application of 3-5\% acetic acid at the transformation zone. $^{8}$

A total of 189 women aged 30-60 years were enrolled in this study. Satyanarayan et al completed a study in the same age group ${ }^{9}$ but our study shows precancerous lesions in women with complaints of suspected abnormal vaginal discharge and dysfunctional uterine bleeding. Laddadet $\mathrm{a}^{10}$ also found precancerous lesions in $70 \%$ of VIA positive women with similar complaints.It is well known that early marriage is a high risk factor for cervical cancer, precancerous lesions were seen in women with a social history of early marriage (<18years)in this study also. Bhattacharya et $\mathrm{a}^{11}$ alsohas reported that incidences of intraepithelial lesions were more common in women whose marriage age was 18 or less. Some studies reported high parity as a high risk factor for cervical cancer but in our study precancerous lesions were found in para 2 , possibly due to early marriage. ${ }^{9}$ 10

In our study VIA and Pap smears were done in all women and cervical biopsies were taken only in cases that were VIA positive, similar studies were done by Begum et al. ${ }^{12}$ Unlike our study Mustafa et $\mathrm{al}^{8}$ performed cervical biopsies in all women with abnormal colposcopic findings whilst Tayyeb et $\mathrm{al}^{13}$ took biopsies not only from women who screened positive but also from women who had an abnormal cervix in colposcopy and advanced lesions but screened negative.

The VIA positive rate in our study was $2.62 \%$ this result was in agreement with the report of Dhaubhadel et $\mathrm{a}^{14}$ that showed the VIA rate as $2.8 \%$. But the result was in disagreement with the findings of Okonkwo ${ }^{15}$ and Bharani et al ${ }^{16}$ who reported $8.4 \%$, and $26 \%$ respectively. These variations in VIA positive rates could be due to differing criteria for the screening of cervical cancer. In the present study the sensitivity of the VIA test was $100 \%$ as there were no cases with a dysplastic lesion which was not picked up by VIA. Similar results were shown by Bharani et $\mathrm{al}^{15}$ and Sheesa et $\mathrm{al}^{17}$ in their studies. The specificity of VIA in our study was $98.4 \%$ which was similar to the findings $98.7 \%$ reported by Harsini et al..$^{18}$ However this result was in disagreement with the findings of Sheesa ${ }^{16}$ and Shammat ${ }^{19}$ who have reported lower VIA specificity of $45 \%$ and $66.7 \%$ respectively. The high rate of sensitivity and specificity of the VIA test indicates that it is also a useful screening tool for cervical cancer. The positive predictive value of VIA was $40 \%$ in this study which was higher than $32 \%$ reported by Bhattacharya et al. ${ }^{11}$ But other studies showed higher positive predictive values, of $73 \%$ and $84.6 \%$ respectively, than this study.,20 Our study shows that there is a chance of over treatmentbut in our context most women were lost to follow up and later presented with the late stages of cervical cancer, thus the "see and treat" method is preferable to preventing cervical cancer in resource poor environments. The present study shows the negative predictive value of VIA was $100 \%$, this result was in agreement with the results of Mahamud et $\mathrm{al}^{2}$ of $98.6 \%$. Unlike our study, Vahedra et $\mathrm{al}^{20}$ showed lower negative predictive value of $85.7 \%$ but since VIA gives immediate results and has a high negative predictive value, women with a negative VIA can be assured immediately that she is precancerous lesion free. Our study shows Pap smears are an effective screening tool but at the same time VIA is a more appropriate screening method for cervical cancer in developing countries. WHO also has recommended VIA as an alternative to cytology to identify patients at risk of cervical cancer. ${ }^{21}$

\section{CONCLUSIONS}

VIA is a quick, safe, easy to perform, cost effective screening process that does not require specialized knowledge or instruction and results are available immediately, thus it has a role inscreening program of cervical cancer in low resource countries like Nepal

\section{Conflict of Interest}

The authors report no conflicts of interest in this work. No violation of human rights and safety.

Funding: Nil. 


\section{REFERENCES}

1. Consul S, Agrawal A, Sharma H, Bansal A, Gutch M, Jain $\mathrm{N}$. Comparative study of effectiveness of Pap smear versus visual inspection with acetic acid and visual inspection with Lugol's iodine for mass screening of premalignant and malignant lesion of cervix. Indian J Med Paediatr Oncol. 2012;33(3):161-5.

2. Mahmud G, Tasnim N, Iqbal S. Comparison of visual inspection with acetic acid and Pap smear in cervical cancer screening at a tertiary care hospital. J Pak Med Assoc. 2013;63(8):1013-6

3. Khodakarami N, Farzaneh F, Aslani F, Alizadeh K. Comparison of Pap smear, visual inspection with acetic acid, and digital cervicography as cervical screening strategies. Arch Gynecol Obstet. 2011;284(5):1247-52.

4. JHPIEGO.Reports on: Cervical cancer preventation (CECAP) situational analysis of awareness, services, referral, and policies in Nepal. Kathmandu: Jhpiego; 2008.

5. Albert SO, Oguntayo OA,Samaila MA. Comparative study of visual inspection of cervix using acetic acid (VIA) and papanicolaou (pap) smears for cervical cancer screening. Ecancer Med Science.2012;6:1-6.

6. Hegde D, Shetty H, Shetty PK, Rai S. Diagnostic value of acetic acid comparing with conventional Pap smear in the detection of colposcopic biopsy-proved CIN. J Cancer Res Ther. 2011;7(4):454-8

7. Hend SS. Can visual inspection with acetic acid be used as an alternative to pap smear in screening cervical cancer? MEFST. 2014;19(3):187-91.

8. Mustafa MM, Jindal CK,Singh PM. Visual inspection using acetic acid for cervical cancer in low resource settings. Med J Armed Forces India. 2010;66:382-4.

9. Satyanarayan I, Athana S, Bhambani S, Shodhani P, Gupta S. A comparative study of cervical cancer screening methods in a rural community setting of North India. Ind $\mathrm{J}$ Cancer. 2014;51(2):124-8.

10. Laddad MM, Kshirsagar N, BahulekarA.Visualisation of the cervix with acetic acid is an alternative to colposcopy in evaluation of cervical cancer and its precursors. Int J Rec Trends SciTech.2013; 8(2):103-5.
11. Bhattacharyya AK, Nath JD, Deka H. Comparative study between pap smear and visual inspection with acetic acid (via) in screening of CIN and early cervical cancer. J Midlife Health. 2015;6(2):53-8

12. Begum SA, Rashid MH, Nessa A, Aziz MA, Zakaria SM, Roy JS. Comparative study between Pap smear and visual inspection using acetic acid as a method of cervical cancer screening. Mymensingh Med J. 2012 Jan;21(1):145-50.

13. Tayyeb R, Khawaja NP, Malik N. Comparision of visual inspection of cervix and Pap smear for cervical cancer screening. J Coll Physicians Surg Pak. 2003;13(4):201-3.

14. Dhaubhadel P, Vaidya A, Choudhary P. Early detection of precursors of cervical cancer with cervical cytology and visual inspection of cervix with acetic Acid. J Nepal Med Assoc. 2008;47(170):71-6.

15. Okonkwo CA, Ize-lyamu I, Deleye O, Ekanem V. Cervical pattern on visual inspection with acetic acid in a faith based population. Ebonyi Med J. 2010;9(2):1-2.

16. Bharani B, Pathak SR. Acetic acid visualisation of the cervix an alternative to colposcopy in evaluation of cervix at risk. J Obstet Gynecol India. 2006;55(6):530-33.

17. Sheesa DM, Mansour SE, Kheder NF, Emam MA. Accuracy of visual inspection with aceticacid in cervical ectopy evaluation. JNEP. 2016;6(3)76-87.

18. Harshini V, Bhandary A, Thunga S. Comparison between Pap smear and VIA as screening for cervical lesions. Indian J Pharm Biol Res. 2013;1(3):1-5.

19. Shammat IM, EissaWA,Mohammed ZI, AlnayalMD, Elsadig M. Direct visualisation of cervix with acetic acid for the detection of premalignant lesions. Sud Med Lab J. 2015;2(2):36-47

20. Vadehra K, Jha R. Visual inspection using acetic acid and pap smear as a method of cervical cancer screening. J Inst Med. $2006 ; 28(1): 1-2$

21. Khan M, Jabun N, Aran U, Sultana SS, Khan S. Visual inspection of cervix with acetic acid a good alternative to pap smear for cervical cancer screening in resource limited setting. JPMA. 2015;65(2):192-5. 